\title{
Cadeias de suprimentos de montadoras dos setores automobilístico e de linha branca - Uma análise comparativa por meio de estudos de caso
}

\section{Supply chains of manufacturers belonging to the automotive and home appliance sectors - A comparative analysis by means of case studies}

\author{
Aline Lamon Cerra ${ }^{1}$ \\ Jonas Lúcio Maia ${ }^{1}$ \\ Alceu Gomes Alves Filho' \\ Edemilson Nogueira ${ }^{1}$
}

\begin{abstract}
Resumo: O objetivo deste artigo é identificar e comparar características estruturais e relacionais de cadeias de suprimentos produtoras de motores para automóveis e de cadeias do setor de linha branca instaladas no Brasil. Foram realizados para isso três estudos de caso em cada um destes setores. Os processos de reestruturação dos dois setores desde meados da década de 1990 apresentaram traços semelhantes, e as montadoras estudadas aumentaram suas bases de fornecimento em função da ampliação da diversidade de modelos e produtos produzidos. Mas há diferenças entre os dois setores no que tange à sazonalidade de demanda, ao comprimento (quantidade de elos) das cadeias e às relações das montadoras com fornecedores de segundo nível (da segunda camada de fornecimento). Os resultados mostram que, em cada setor, mesmo quando possuem objetivos estratégicos e prioridades competitivas de produção em alguma medida similares, as empresas adotam práticas e configurações de Gestão da Cadeia de Suprimentos (GCS) distintas. Em cada um dos setores, há diferenças estruturais e relacionais importantes entre as cadeias de suprimentos. As montadoras estudadas apresentam diferentes níveis de terceirização de componentes, têm suas plantas posicionadas a distâncias distintas dos respectivos conjuntos de fornecedores e possuem diferentes políticas de suprimentos e números de fornecedores.
\end{abstract}

Palavras-chave: Cadeias de Suprimentos. Gestão da Cadeia de suprimentos. Setor Automobilístico. Setor de Linha branca.

\begin{abstract}
The main goal of this article is to identify and compare structural and relational characteristics of Brazilian supply chains that produce car engines and home appliances. With this purpose we carried out three case studies in each of these industries. The restructuring of the two industries since mid-1990s had similar traits, and automakers increased their supply bases due to the expansion of the diversity of products. But there are differences between the two groups regarding the seasonality of demand, the number of tiers in the supply chains and the relationships between assemblers and second tier suppliers. The results show that, in each sector, even when companies have similar competitive priorities and strategic objectives, they adopt distinct supply chain configurations and management practices. In each sector, there are structural differences among supply chains in the levels of outsourcing, in the geographic distance between assemblers and suppliers, in procurement policies and in the number of suppliers.
\end{abstract}

Keywords: Supply Chains. Supply Chain Management. Automotive Industry. Home Appliance Industry.

\section{Introdução}

O interesse pela Gestão da Cadeia de Suprimentos (GCS) se intensificou a partir da década de 1990 devido, principalmente, a movimentos de desverticalização e especialização das empresas, à intensificação da competição em níveis nacional e internacional e, também, ao potencial de contribuição da GCS ao aumento de competitividade das empresas. A GCS pode proporcionar, dentre outras vantagens, reduções de custos e maior agilidade nas entregas (LUMMUS; VOKURKA, 1999). Este interesse pelo tema tem motivado acadêmicos a desenvolver conceitos e métodos para a análise das características estruturais e relacionais das cadeias de suprimentos.

Alves Filho et al. (2004) consideram a GCS um corpo de conhecimentos ainda em construção. Indicam que a literatura que trata do tema, tanto a de

\footnotetext{
' Departamento de Engenharia de Produção, Universidade Federal de São Carlos - UFSCar, Rodovia Washington Luís, Km 235, CP 676, CEP 13565-905, São Carlos, SP, Brasil, e-mail: alinelc@terra.com.br, jonas.lucio.maia@ gmail.com, alceu@dep.ufscar.br, edn@dep.ufscar.br
}

Recebido em 29/12/2012 — Aceito em 5/3/2014

Suporte financeiro: Nenhum. 
cunho mais prescritivo como a empírica, assume um conjunto de pressupostos que, em muitos casos, são enunciados como princípios norteadores de práticas de gestão mais eficazes, como se o conjunto destes pudesse ser adotado e ser o mais eficaz e eficiente em quaisquer circunstâncias. Nesta linha de discussão, os autores sugerem que as abordagens de GCS devem incluir uma etapa inicial de "verificação dos pressupostos" ou de identificação da configuração da cadeia de suprimentos, pois, desse modo, poderiam ser desvendados os tipos de contextos em que as relações entre as empresas e a GCS poderiam se desenvolver.

Pode-se também acrescentar que empresas com grande influência em cadeias de suprimentos, como é o caso das montadoras no setor de motores e no setor de linha branca, desenvolvem relações com seus fornecedores e implementam práticas relacionadas à GCS em função de sua orientação estratégica ou de suas prioridades competitivas de produção.

Neste trabalho, pretende-se iniciar a discussão de tais proposições especificamente em algumas cadeias de suprimentos do segmento de motores para automóveis e em algumas cadeias do setor de linha branca. Busca-se para isso comparar como são articuladas, nas diversas cadeias de suprimentos dos dois setores, as características estruturais e relacionais das cadeias, algumas das práticas implementadas de GCS e as prioridades competitivas de produção.

No setor automobilístico brasileiro, as montadoras racionalizaram suas atividades, concentraram-se em competências essenciais e terceirizaram um maior número de atividades nas cadeias de suprimentos (MAIA, 2006; CERRA; MAIA; ALVES FILHO, 2007). O contexto das cadeias de suprimentos dessas empresas vem sendo influenciado por alterações resultantes da instalação de novas montadoras e da consolidação e desnacionalização do setor de autopeças, bem como do impacto de fenômenos específicos ao cenário brasileiro como (1) a utilização dos motores $1000 \mathrm{cc}$, no início dos anos 2000 , e seus modelos derivados como o 1300cc e 1400cc mais recentemente; (2) e de motores flexíveis, que podem operar com gasolina e/ou álcool (além de nafta e gás natural veicular em alguns casos).

$\mathrm{O}$ segundo setor aqui estudado abrange a fabricação de "produtos da linha branca", uma denominação dada aos eletrodomésticos não portáteis que, devido às suas características peculiares, são considerados como um segmento específico. São eles: refrigeradores, lavadoras automáticas, freezers verticais e horizontais, lava-louças, secadoras de roupas automáticas, fogões, condicionadores de ar e fornos micro-ondas (ROTTA, 2004).

No Brasil, de acordo com Cunha (2003), a década de 1990 foi marcada pela desnacionalização da indústria de eletrodomésticos de linha branca, acompanhada pela reconfiguração patrimonial das empresas e introdução de inovações tecnológicas e organizacionais, com aumento de eficiência e expansão das exportações. O movimento de reestruturação produtiva se disseminou das montadoras para os fornecedores distribuídos ao longo da cadeia de linha branca doméstica, principalmente por meio dos programas de qualificação e desenvolvimento de fornecedores. Ainda segundo Cunha (2003), as empresas do setor passaram a externalizar atividades produtivas muito intensivas em trabalho e/ou muito complexas, que dependem de fornecedores especializados, tendo como objetivos a redução de custos e aumento da eficiência produtiva e da competitividade.

Comparadas às montadoras do setor automobilístico, a intensidade da terceirização de componentes observada nas empresas do setor de linha branca pode ser considerada menor, embora estas tenham se desverticalizado consideravelmente após serem adquiridas por empresas multinacionais (CERRA et al., 2008).

O nível de terceirização do setor de linha branca varia de empresa para empresa e também conforme o produto (por exemplo, uma determinada empresa apresenta nível alto de terceirização na fabricação de lavadoras, o que não ocorre em relação à fabricação de fogões). Assim como no setor automotivo, foi a partir da metade da década de 1990 que se intensificou o processo de reestruturação produtiva e organizacional nas empresas da linha branca, que se diferenciaram, diversificaram linhas de produtos, ampliaram capacidades produtivas e modernizaram plantas existentes ou instalaram novas plantas.

Considerando os contextos das cadeias de suprimentos e das empresas situadas nos dois setores examinados, pretende-se abordar neste trabalho as seguintes principais questões de pesquisa: Quais são as semelhanças e as diferenças entre as cadeias de suprimentos estudadas nestes dois setores? E, mais especificamente, quais são os principais aspectos (relativos às estruturas das cadeias e às relações entre as empresas que as compõem) que influenciam e diferenciam as cadeias de suprimentos das montadoras de motores e da linha branca?

No que diz respeito aos aspectos relativos à estrutura das cadeias, são considerados, em cada cadeia, os clientes, os principais fornecedores de primeiro nível, a política de suprimentos das montadoras, o fornecimento exclusivo, além do porte e localização dos fornecedores relevantes.

Quanto aos aspectos relacionais, são levantados, em cada cadeia, os critérios utilizados pelas montadoras para selecionar fornecedores, como estes são avaliados, o desenvolvimento de fornecedores, a logística de transporte e as relações com os vários níveis da cadeia de suprimentos. Procura-se ainda identificar as prioridades competitivas de produção adotadas pelas empresas montadoras, pois tais prioridades 
podem condicionar diversas decisões relativas às características estruturais e relacionais implementadas nas cadeias.

São estudadas, nesta pesquisa, três cadeias de suprimentos em cada um dos setores pesquisados. Considerando o caráter exploratório da pesquisa e a relevância das empresas e dos setores estudados, espera-se apresentar indícios que fomentem a discussão sobre aspectos importantes da GCS.

$\mathrm{O}$ artigo se encontra estruturado em quatro seções, além desta introdução. Na primeira, são apresentados conceitos a respeito do tema GCS. Em seguida, descreve-se o método utilizado para a realização da pesquisa. Na terceira seção, são apresentados os resultados da pesquisa de campo e, finalmente, na última seção, são apresentadas as conclusões e os comentários finais.

\section{Gestão da Cadeia de Suprimentos}

Ao iniciar a discussão sobre Gestão da Cadeia de Suprimentos, é necessário situar o conceito em meio à profusão de termos relacionados, tanto alguns que surgiram recentemente quanto outros que são anteriores ao próprio surgimento da GCS.

As cadeias (ou redes) de suprimentos estão contidas nas chamadas "cadeias produtivas", que representam genericamente os diversos setores industriais existentes, tais como a cadeia automotiva, metalmecânica, eletrônica, dentre outras (PIRES, 2004). Segundo Alvarez (2004), o conceito de cadeia produtiva tem origem na Economia e refere-se a um conjunto de empresas que mantém relações de suprimentos entre si e fornecem um determinado tipo de produto para um mercado final, como é o exemplo do mercado de automóveis.

De acordo com Mentzer et al. (2001, p. 4),

[...] uma cadeia de suprimentos é definida como um conjunto de três ou mais entidades (organizações ou indivíduos) envolvido diretamente nos fluxos a montante e a jusante de produtos, serviços, finanças e/ou informação de uma fonte a um cliente.

Neste trabalho, considera-se que uma cadeia de suprimentos engloba todos os estágios (clientes, varejistas, distribuidores, fabricantes e fornecedores) envolvidos, direta ou indiretamente, no atendimento de um pedido ao cliente (CHOPRA; MEINDL, 2003). Para Novaes (2001), citado por Padovani (2007), sua complexidade evolui à medida que aumentam o número de empresas participantes e o número de transações entre organizações.

Quanto à "Gestão da Cadeia de Suprimentos" (GCS), cabe mencionar, conforme indicam Teixeira e Lacerda (2010), que cada definição varia dependendo da perspectiva teórica utilizada ao abordar o objeto. Burgess, Singh e Koroglu (2006) destacam que parece haver pouco consenso quanto à expressão Gestão da Cadeia de Suprimentos e à sua definição.

Neste trabalho, a Gestão da Cadeia de Suprimentos é entendida como

[...] a integração de processos de negócios-chave do usuário final até os fornecedores originais que proveem produtos, serviços e informação que adicionam valor para os clientes e para os stakeholders. (LAMBERT; COOPER; PAGH, 1998, p. 1).

Observa-se, desde os anos 1990, significativa expansão da literatura sobre Gestão da Cadeia de Suprimentos e sobre o conjunto de técnicas que apoia sua implementação. Nesse contexto,

[...] a estrutura e o relacionamento são dimensões importantes para o entendimento da cadeia de suprimento e sua dinâmica [...] (PIRES; SACOMANO NETO, 2010, p. 173).

Para Lambert, Cooper e Pagh (1998), três dimensões estruturais são importantes para descrever, analisar e gerenciar uma cadeia de suprimentos: a estrutura horizontal, a estrutura vertical e a posição horizontal da empresa focal na cadeia de suprimentos. A estrutura horizontal refere-se ao número de níveis da cadeia de suprimentos, enquanto que a estrutura vertical refere-se ao número de fornecedores/clientes representados em cada nível. Quanto à posição da empresa focal na cadeia, pode ser próxima à fonte primária de suprimentos, próxima ao cliente final, ou em algum lugar entre estes pontos extremos da cadeia.

Outra perspectiva bastante discutida na literatura sobre cadeia de suprimentos refere-se aos diversos tipos de relacionamentos e suas motivações. As relações mantidas entre uma empresa focal e seus parceiros refletem o nível de integração e coordenação entre as empresas, em função de objetivos que tenham em comum na gestão de uma cadeia de suprimentos. (OLIVEIRA; LEITE, 2010).

Fazem parte do conjunto das características relacionais as estratégias e políticas adotadas pelas empresas. Em cadeias de suprimentos "coordenadas" por unidades montadoras de produtos finais, com grande poder de barganha, cabe investigar em que medida e de que modo as estratégias e políticas adotadas por tais montadoras condicionam os comportamentos das cadeias.

Abordando características estruturais e relacionais, Alves Filho et al. (2004) destacam alguns dos principais pressupostos que diversos autores adotam - em geral, implicitamente - ao discutirem a GCS e ao proporem métodos e práticas. Apresentam e agrupam tais pressupostos em quatro subconjuntos: ambiente competitivo; alinhamento estratégico das organizações e repartição de ganhos; estrutura da cadeia de suprimentos; e relações entre empresas da 
cadeia. A seguir, faz-se um breve comentário a respeito de cada subconjunto de pressupostos com o intuito de evidenciar aspectos importantes relacionados às características estruturais e relacionais das cadeias de suprimentos que serão considerados na pesquisa a ser apresentada.

\subsection{Ambiente competitivo}

$\mathrm{O}$ primeiro subconjunto de pressupostos se refere à maneira com que praticantes e pesquisadores percebem o ambiente competitivo. No novo ambiente entende-se que a competição passa a ocorrer entre cadeias de suprimentos inteiras e não apenas entre empresas isoladas (CHRISTOPHER, 1992; LAMBERT; COOPER; PAGH, 1998).

Pressupõe-se que, por fazerem parte de cadeias de compradores e fornecedores, as empresas devem buscar, conjuntamente, maximizar o valor agregado aos produtos, de forma a tornar toda a cadeia competitiva, e compartilhar os ganhos obtidos por meio de reduções de custos e de aumento da qualidade (CAMPOS, 1992 apud NEUMANN; RIBEIRO, 2004).

\subsection{Alinhamento estratégico das organizações e repartição de ganhos}

O segundo grupo de pressupostos deriva do primeiro. Se agora a competição ocorre entre cadeias inteiras, as companhias devem ter suas estratégias alinhadas, de forma que ações individuais gerem ganhos para toda a cadeia. A contrapartida do alinhamento estratégico seria uma distribuição de ganhos equânime entre as empresas, de acordo com os esforços e investimentos feitos por cada uma. (CERRA; MAIA; ALVES FILHO, 2007).

De acordo com Handfield e Nichols (1999) apud Assumpção (2003), reconhece-se a importância do alinhamento das estratégias das empresas com a da cadeia de suprimentos para melhoria de desempenho na relação entre fornecedores e clientes. Por meio da colaboração, parceiros da cadeia de suprimentos são integrados em uma rede em que as metas, atividades operacionais e estratégias são efetivamente alinhadas (CHENG; CHEN; MAO, 2010). No mesmo sentido, Wong et al. (2011) afirmam que a necessidade de alinhamento na cadeia é indiscutível e é resultado de um ajuste em termos de objetivos, estruturas e processos internos e entre diferentes funções e membros em uma cadeia de suprimentos.

Ainda no que diz respeito ao alinhamento estratégico, pode-se propor que as prioridades competitivas de produção, como definidas por Garvin (1993), de empresas montadoras, devem condicionar parte das decisões estruturais e relacionais a montante na cadeia de suprimentos.

\subsection{Estrutura da Cadeia de Suprimentos}

O terceiro subconjunto contempla aspectos relativos à estrutura da cadeia de suprimentos, isto é, aos papeis que as empresas e unidades produtivas devem desempenhar nas cadeias de suprimentos. Para um funcionamento eficaz e eficiente, os fornecedores devem estar organizados em níveis (camadas ou elos), em número relativamente pequeno (MIRANDA, 2002; TAN, 2002), a coordenação de processos e atividades deve ser facilitada pelo uso de tecnologia de informação, promovendo um fluxo bidirecional de materiais, de informação e financeiro (LAMBERT; EMMELHAINZ; GARDNER, 1996). Além disso, cada empresa deve procurar reduzir a complexidade de suas próprias atividades (reduzindo assim a complexidade da cadeia como um todo).

Neste terceiro subconjunto de pressupostos, as estratégias de outsourcing são consideradas importantes, pois reforçam a estrutura organizada e hierarquizada e impactam as relações entre as empresas, comentadas a seguir no quarto grupo de pressupostos. Segundo Tratt, Moraes e Alperstedt (2006), outsourcing é a expressão em inglês para o termo terceirização. Pode ser definido, de acordo com Ellram e Billington (2001), como a transferência da produção de mercadorias e serviços para terceiros. A terceirização pode ser acompanhada pelo desenvolvimento de uma relação de parceria entre a empresa que terceiriza e o terceirizado e assim ter impactos tanto na estrutura quanto nas relações entre as empresas que compõem a cadeia. Pires (2004) também indica a tendência de uma reestruturação e consolidação da base de fornecedores e clientes, procurando-se construir parcerias.

Para que haja coordenação na cadeia, todas as ações das empresas devem estar articuladas. Isto requer que, em cada estágio, cada empresa leve em consideração o impacto que suas ações exercem sobre as demais empresas da cadeia (CHOPRA; MEINDL, 2003). Nesse sentido, o acesso de cada empresa às informações sobre as atividades em todos os elos é crucial para a tomada de decisão e para a melhoria do desempenho da cadeia de suprimentos (COSTA; MAÇADA, 2009). No que se refere à tecnologia de informação, Cheng, Chen e Mao (2010) acrescentam que há evidências de que sua eficácia tem efeito positivo em colaboração, encorajando a comunicação interfirmas. Uma empresa focal ou líder usualmente exerce alguma influência entre os membros, determinando muitas vezes o modo de coordenação da cadeia de suprimentos (OLIVEIRA; LEITE, 2010). 


\subsection{Relações entre empresas da Cadeia de Suprimentos}

O quarto grupo se refere às relações entre as empresas e unidades produtivas na cadeia de suprimentos. Abrange, em linhas gerais, as relações cooperativas e de longo prazo, as parcerias entre as empresas, o desenvolvimento de fornecedores e o envolvimento destes em atividades conjuntas de $\mathrm{P} \& \mathrm{D}$ e/ou desenvolvimento de produtos.

Segundo Hilsdorf, Rotondaro e Pires (2009), os novos parâmetros de competitividade na economia globalizada requerem o estabelecimento de vínculos mais fortes e duradouros com seus clientes e fornecedores, de forma a estabelecer uma cadeia capaz de fazer frente a esses novos parâmetros e obter vantagens para todos os seus componentes. A dependência mútua entre os membros da cadeia incentiva a cooperação (BANDEIRA; MELLO; MAÇADA, 2009). E, para Lamming (1993), a cooperação entre empresas promove a racionalização da cadeia de suprimentos. Já Cheng, Chen e Mao (2010) ressaltam a importância para a GCS da colaboração mais ampla e profunda não apenas sob a perspectiva da integração vertical, mas também do ponto de vista horizontal.

De acordo Christopher (1992), ao fazer a seleção de fornecedores e também ao procurar os critérios para a redução da base de fornecedores, a organização deve buscar aqueles que sejam capazes de aceitar o desenvolvimento de um relacionamento de longo prazo com base na confiança mútua. Santos, Kato e Frega (2006) apontam o relacionamento de longo prazo como um aspecto fundamental para o desenvolvimento de parcerias entre fornecedores e compradores. Segundo Pires e Sacomano Neto (2010), a efetiva gestão da cadeia de suprimentos somente vai ocorrer se existir confiança mútua (trust) entre as empresas que dela participam.

Os compradores nos vários elos das cadeias de suprimentos devem procurar selecionar fornecedores dispostos e capazes de atender a suas especificações. Martins (1999) aponta que, para a definição dos perfis dos fornecedores, as empresas devem observar um conjunto de habilidades que atendam a determinados critérios. Essas habilidades estão associadas a capacidades tecnológicas, de qualidade, de custo e de entrega. Já Park et al. (2010) ressaltam que o processo de seleção é complexo por duas razões: a) fornecedores podem ser avaliados por mais de um critério e b) cada fornecedor tem diferentes especialidades e então diferentes critérios devem ser adotados.

As empresas têm investido em desenvolvimento de fornecedores, o que abrange qualquer atividade que um comprador empreende para melhorar as capacidades de desempenho de seus fornecedores e com isto satisfazer suas próprias necessidades de compras no curto ou longo prazo (HANDFIELD; KRAUSE; SCANNELL, 2000; PARK et al., 2010). Com frequência, são feitas avaliações formais dos fornecedores e muitas empresas têm estabelecido programas de treinamentos para seus fornecedores visando auxiliá-los a alcançar metas de desempenho superiores.

Outra prática que tem se expandido no contexto da GCS é o envolvimento conjunto das empresas em P\&D (ELLRAM, 1991 apud MIRANDA, 2002) e o envolvimento de fornecedores no processo de desenvolvimento e fabricação de novos produtos (TAN, 2002).

O chamado "Early Supplier Involvement (ESI)", ou seja, o envolvimento de fornecedores desde a fase inicial do projeto do produto permite que o fornecedor traga a sua competência e know-how a serviço de um produto desenvolvido mais rapidamente, a custo menor e com qualidade melhor (SANTOS; FORCELLINI, 2005).

Sumarizando, partindo-se do pressuposto de que a competição se dá entre cadeias de suprimentos, os demais pressupostos dele decorrem e são assumidos com a perspectiva de organizar e coordenar as cadeias para que se mantenham contínua e sustentadamente eficientes, eficazes e competitivas, com ganhos para todas as empresas e unidades produtivas participantes.

\section{Método}

Este trabalho foi realizado basicamente em duas etapas: revisão da literatura acerca dos tópicos associados ao tema e desenvolvimento de uma pesquisa de campo nos setores de fabricação de motores para automóveis e de fabricação de produtos da linha branca. Esta última foi realizada por meio de estudos de caso, método apropriado, segundo Yin (2005), à investigação de um fenômeno contemporâneo, em seu contexto real, por meio de múltiplas fontes de evidência: entrevistas, observações diretas, documentos, etc. Para o autor, a possibilidade de utilização de várias fontes de evidência é considerada uma das particularidades da pesquisa baseada em estudos de caso.

Os estudos de caso foram realizados entre os anos de 2007 e 2009, fundamentados em entrevistas semiestruturadas. Nas empresas, as pessoas entrevistadas eram preferencialmente diretores industriais, além de gerentes de compras/suprimentos.

Foram então estudadas três montadoras do setor automobilístico, sendo duas estabelecidas (que iniciaram suas atividades produtivas no período de instalação da indústria automobilística brasileira e desenvolvem atualmente atividades de P\&D no Brasil) e uma entrante (que apresenta extrema centralização das atividades de engenharia e de P\&D no exterior, sobretudo em relação aos estágios de Desenvolvimento 
de Produtos (DP)). No setor de linha branca, também foram estudadas três montadoras, sendo uma delas nacional.

A discussão das características das cadeias de suprimentos envolveu o levantamento e a análise das estruturas das cadeias e das relações entre as empresas que as compõem, procurando-se capturar elementos práticos que subsidiassem a compreensão de como estão ocorrendo (e se estão ocorrendo) os principais direcionamentos preconizados na teoria sobre GCS e que foram sintetizados na seção anterior. Destaca-se que, neste estudo, são focalizadas as cadeias de suprimentos a partir das montadoras e a montante.

\section{Apresentação dos resultados}

São apresentados nesta seção os resultados da pesquisa de campo realizada. Considerando a grande quantidade de informações envolvida na descrição de cadeias e empresas, optou-se por uma apresentação no formato tabular e textual, com o objetivo de proporcionar uma visão abrangente e comparativa.

\subsection{Características gerais das empresas estudadas}

Na Tabela 1, as três primeiras colunas se referem às montadoras de motores (MM), e as três colunas restantes, às montadoras do setor de linha branca (MLB).

No que diz respeito ao setor automotivo, considerando o segmento de veículos leves, distinguem-se, neste trabalho, os termos "montadoras de motores" e "montadoras de automóveis". As primeiras são empresas que atuam na produção dos motores, geralmente manufaturando determinados componentes e realizando a montagem de diversas partes/sistemas adquiridas externamente de fornecedores. As segundas, por outro lado, atuam na produção dos veículos em si, agregando, além dos motores manufaturados pelas primeiras, todos os diversos outros itens que constituem o veículo. Esta distinção é importante, pois, diferentemente do que ocorre em veículos pesados e agrícolas, as montadoras de motores para veículos leves em geral pertencem ao mesmo grupo econômico de suas montadoras de automóveis (MAIA, 2006).

Em termos de suas características gerais, dentre as três montadoras automotivas, a MM3 se diferencia significativamente das duas primeiras. A MM3 (entrante) se instalou no Brasil após os anos 1990 e apresenta menor porte, linhas de produtos menos diversificadas e menor capacidade de produção, conforme indica a Tabela 1. Por operar com capacidade ociosa, não sofre pressões por flexibilidade, canalizando suas iniciativas para qualidade e custo. No caso das montadoras MM1 e MM2, por outro lado, flexibilidade de mix de produtos é a prioridade competitiva mais importante. Além desta, a MM1 está voltada à capacidade de mix de produção.

Assim, em cada setor, as empresas escolhem suas prioridades competitivas, considerando principalmente o comportamento de seus concorrentes e as condições do mercado em que se inserem.

Tabela 1. Características gerais das montadoras.

\begin{tabular}{|c|c|c|c|c|c|c|}
\hline & \multicolumn{3}{|c|}{ Setor Automobilístico } & \multicolumn{3}{|c|}{ Setor de Linha Branca } \\
\hline & \multicolumn{3}{|c|}{ Montadoras de Motores } & \multicolumn{3}{|c|}{ Montadoras de Linha Branca } \\
\hline & \multicolumn{2}{|c|}{ Estabelecidas } & \multirow{2}{*}{$\begin{array}{c}\text { Entrante } \\
\text { MM } \\
\mathbf{3}\end{array}$} & \multicolumn{2}{|c|}{ Multinacionais } & \multirow{2}{*}{$\begin{array}{c}\text { Nacional } \\
\text { MLB } \\
6\end{array}$} \\
\hline & $\underset{1}{\mathrm{MM}}$ & $\begin{array}{c}\mathrm{MM} \\
2\end{array}$ & & $\begin{array}{c}\text { MLB } \\
4\end{array}$ & $\begin{array}{c}\text { MLB } \\
5\end{array}$ & \\
\hline $\begin{array}{l}\text { Funcionários da } \\
\text { planta estudada }\end{array}$ & 850 & $\begin{array}{l}1900 \text { (inclui } \\
\text { produção de } \\
\text { automóveis) }\end{array}$ & 420 & 1900 & 1600 & 200 \\
\hline $\begin{array}{c}\text { Produtos } \\
\text { (feitos nas } \\
\text { plantas } \\
\text { estudadas) }\end{array}$ & $\begin{array}{l}\text { Motores } 1.0, \\
1.4 \text { e } 1.6,1.9 \\
\text { (diesel) e } 2.0\end{array}$ & $\begin{array}{l}\text { Motores } 1.0, \\
1.4,1.6,1.8, \\
2.0,2.2 \text { e } 2.4\end{array}$ & $\begin{array}{c}\text { Motores } 1.4 \\
\text { e } 1.6\end{array}$ & $\begin{array}{l}\text { Lavadoras de } \\
\text { roupas, freezers } \\
\text { e fogões }\end{array}$ & Fogões & $\begin{array}{l}\text { Lavadoras de roupa } \\
\text { semiautomáticas, } \\
\text { secadoras } \\
\text { centrífugas de } \\
\text { roupas, etc. }\end{array}$ \\
\hline $\begin{array}{c}\text { Capacidade } \\
\text { instalada de } \\
\text { produção }\end{array}$ & $\begin{array}{c}65.000 \\
\text { motores/mês }\end{array}$ & $\begin{array}{c}71.000 \\
\text { motores/mês }\end{array}$ & $\begin{array}{c}30.000 \\
\text { motores/mês }\end{array}$ & $\begin{array}{c}150.000 \\
\text { unidades/mês }\end{array}$ & $\begin{array}{l}250.000 \\
\text { unidades/ } \\
\text { mês }\end{array}$ & $\begin{array}{c}100.000 \\
\text { unidades/mês }\end{array}$ \\
\hline Produção Real* & $\begin{array}{c}65.000 \\
\text { motores/mês }\end{array}$ & $\begin{array}{c}59.000 \\
\text { motores/mês }\end{array}$ & $\begin{array}{c}16.000 \\
\text { motores/mês }\end{array}$ & $\begin{array}{c}130.000 \\
\text { unidades/mês }\end{array}$ & $\begin{array}{l}170.000 \\
\text { unidades/ } \\
\text { mês }\end{array}$ & $\begin{array}{c}50.000 \\
\text { unidades/mês }\end{array}$ \\
\hline
\end{tabular}

*Média estimada com base no volume anual (linha branca apresenta sazonalidade). 
Considerando o grau de autonomia tecnológica apresentado pelas subsidiárias automobilísticas locais, observa-se que as montadoras (de motores) estabelecidas apresentaram evolução, pois passaram de uma situação em que apenas adaptavam motores desenvolvidos no exterior (para o mercado brasileiro) para uma posição em que dedicam grande parte de suas atividades tecnológicas ao desenvolvimento de produtos para o mercado local e mercados emergentes. A entrante não desenvolvia produtos no Brasil no momento da pesquisa - o entrevistado declarou que a empresa almejava fazê-lo - apresentando total dependência da matriz estrangeira. As informações obtidas nas entrevistas indicam que essas montadoras apresentam diferentes níveis de terceirização na fabricação dos componentes para motores. A Montadora 1 é a mais terceirizada, faz a usinagem dos blocos dos motores internamente e terceiriza os demais componentes, inclusive a fundição; a Montadora 3 (a entrante) ocupa uma posição intermediária, fazendo internamente a usinagem do bloco, do virabrequim, da biela e dos cabeçotes, terceirizando os demais componentes; e a Montadora 2 pode ser considerada a menos terceirizada das três, embora recentemente tenha deixado de produzir internamente alguns componentes. Faz internamente alguns componentes fundidos: bloco, cabeçote, virabrequim, eixo comando e biela e terceiriza a usinagem e os demais componentes.

A Montadora 1 pode ser considerada como uma das montadoras de motores, dentre as instaladas no Brasil, com maior nível de terceirização na fabricação dos componentes principais. Em 2006, a montadora optou por usinar $50 \%$ dos cabeçotes utilizados em seus motores, instalando em seu terreno a linha de produção necessária para isso. No entanto, evidências indicam que este movimento se refere a um fato isolado e não a uma tendência à estratégia de integração vertical. Tal decisão se deveu aos níveis insatisfatórios de qualidade apresentados pelo fornecedor e aos problemas decorrentes então vivenciados pela montadora.

No setor de linha branca, dentre as montadoras estudadas, a MLB6 se diferencia bastante das duas primeiras. A MLB6 (nacional) possui apenas uma planta, a estudada, apresentando menor porte e desenvolvendo e fabricando produtos mais simples. Iniciou suas atividades produtivas mais recentemente e, embora tenha crescido, apresenta volumes de produção bem menores do que das outras montadoras estudadas. Sua prioridade competitiva mais importante é custos e também vem buscando a flexibilidade de mix de produtos. Apesar de ter diversificado seus produtos, está voltada a diferentes fatias do mercado consumidor, ou seja, às camadas mais populares.

As Montadoras MLB4 e MLB5 iniciaram suas atividades em seus países de origem há mais tempo e, desde então, passaram por joint ventures, aquisições de outras empresas e incorporação de outras marcas de produtos deste setor industrial. Cabe mencionar que, quando adquiridas pelos grandes grupos, os conhecimentos tecnológicos locais acumulados (assim como as instalações) foram de certa forma aproveitados, ao mesmo tempo que as unidades foram se modernizando e incorporando outras inovações.

As prioridades competitivas de produção das duas montadoras aparecem em ordens diferentes. Para a MLB4, a flexibilidade de mix de produtos está à frente de custos, ao passo que, para a MLB5, a prioridade custos antecede a flexibilidade de volume de produção.

Estas montadoras também têm participado do desenvolvimento global de produtos, tanto como sede de projetos como, em alguns casos, fazendo tropicalização. Assim, as montadoras MLB4 e MLB5 desenvolvem produtos no Brasil, sendo que a primeira delas está voltada ao mercado local; a MLB6, no entanto, desenvolve produtos com plataformas globais. Já a nacional MLB6 desenvolve produtos localmente, menos sofisticados do ponto de vista tecnológico do que os desenvolvidos pelas outras duas montadoras estudadas, para consumidores de camadas mais populares.

A linha branca enfrenta períodos de sazonalidade da demanda, o que a faz operar com capacidade ociosa em determinados períodos. No setor automotivo, este caráter sazonal tende a ser menos pronunciado, e as montadoras conseguem operar com estoques de forma a ajustar capacidade e demanda.

No setor de linha branca, as inovações em produtos são mais frequentes e incrementais do que no setor automobilístico. Isto está relacionado ao fato de seus produtos serem mais simples do ponto de vista tecnológico do que os motores.

Em ambos os setores, as matrizes são fontes importantes de tecnologia, sendo que algumas das empresas possuem no Brasil setores de desenvolvimento de produto e de processo já bem estruturados, com alguma autonomia em desenvolvimento de certos tipos de produtos e em determinadas áreas (ou segmentos tecnológicos). As empresas contam (de diferentes formas) com a participação dos fornecedores para aperfeiçoarem seus produtos e processos.

Em geral, as montadoras deste último setor, quando foram adquiridas por grupos multinacionais, passaram por um processo de terceirização de componentes. Durante essa fase, desenvolveram fornecedores que atualmente se encontram habilitados à fabricação (e em certos casos também ao desenvolvimento) de partes importantes de seus produtos.

Indicar qual das montadoras do setor de linha branca é a mais terceirizada não é uma tarefa simples, já que fabricam produtos diferentes e apresentam graus diferenciados de terceirização para os diversos produtos. O produto "fogão" é o único comum a duas das montadoras (MLB4 e 5); e, especificamente 
neste caso, pode-se dizer que a Montadora 4 é mais terceirizada, pois adquire externamente certas partes dos fogões que a Montadora 5 faz internamente (ex.: a cavidade do forno).

O nível de terceirização do setor de linha branca varia de empresa para empresa e também conforme o produto (por exemplo, uma determinada empresa apresenta nível alto de terceirização na fabricação de lavadoras, o que não ocorre em relação à fabricação de fogões).

Assim como no setor automotivo, foi a partir da metade da década de noventa que se intensificou o processo de reestruturação produtiva nas empresas da linha branca, que se diferenciaram e sofisticaram os produtos, ampliaram as capacidades produtivas e modernizaram plantas existentes ou instalaram novas plantas.

\subsection{Estrutura das Cadeias de Suprimentos}

Uma vez tratados os aspectos gerais das empresas e de suas cadeias, a Tabela 2 traz as informações das estruturas das cadeias analisadas.

No setor automotivo, as Montadoras 1 e 2 estão localizadas próximas de seus fornecedores principais. Já a Montadora 3 encontra-se mais distante deles, considerando os fornecedores situados no Brasil (Cerca de $60 \%$ dos fornecedores estão no exterior).

A Montadora 1 possui cerca de 150 fornecedores diretos e vem aumentando o número deles, conforme tem aumentado a diversidade de seus produtos. A política de suprimentos desta montadora consiste em ter, predominantemente, dois fornecedores por tipo de componente terceirizado e, deste modo, incentiva a concorrência entre eles, aumentando seu poder de barganha nas negociações. Para alguns componentes, a Montadora 1 possui apenas um, para outros, possui três fornecedores.

A Montadora 2 possui aproximadamente 100 fornecedores, sendo que pretende reduzir o número deles e concentrar o fornecimento de cada componente em um único fornecedor, desde que este tenha capacidade de produção suficiente para suprir a demanda da montadora. Desse modo, a Montadora
2 possui, predominantemente, um fornecedor por componente terceirizado.

Já a Montadora 3 possui 92 fornecedores diretos, 60 deles situados fora do Brasil. Cabe mencionar que a maior parte dos fornecedores situados no Brasil são comuns às demais montadoras, embora haja alguns localizados mais próximos da montadora, como é o caso de um fornecedor que a atende exclusivamente.

A política de suprimentos atual consiste em manter um fornecedor por item terceirizado. No entanto, dada a busca pela nacionalização dos componentes, a Montadora 3 pretende passar a ter, no médio prazo, dois fornecedores no caso dos itens que à época da entrevista eram apenas importados: um no exterior e um localizado no Brasil.

As cadeias apresentam diferenças quanto ao porte e à capacidade tecnológica dos fornecedores que as compõem. No que se refere ao porte dos fornecedores, a Montadora 1 se diferencia das outras duas. Além de apresentar empresas de grande e médio portes em sua cadeia, como as montadoras 2 e 3 , apresenta um conjunto de empresas de pequeno porte, geralmente de capital nacional.

Nas cadeias de suprimentos das montadoras 1 e 2, não há fornecedores exclusivos, mas há fornecedores que destinam quase toda sua produção a essas montadoras. A Montadora 3 possui um fornecedor exclusivo: uma empresa subsidiária de uma multinacional que fornece conjuntos balancins. Por ter impacto nas relações entre empresas, essa característica da cadeia - a existência de fornecedores exclusivos - será tratada a seguir.

As cadeias, principalmente as do segmento dos componentes metalmecânico, apresentam poucos níveis ou camadas de fornecimento, possuindo, no segundo nível de suprimentos, empresas fornecedoras de produtos que são, muitas vezes, menos sofisticados tecnologicamente. Neste segmento, já no segundo ou terceiro nível de suprimentos pode-se encontrar empresas metalúrgicas e siderúrgicas, fornecedoras de matérias-primas. Desse modo, as empresas no primeiro nível de fornecimento das montadoras sofrem fortes pressões: de um lado, das montadoras, de outro, de grandes empresas fornecedoras de matérias-primas.

Tabela 2. Estrutura das Cadeias de Suprimentos.

\begin{tabular}{|c|c|c|c|c|c|c|}
\hline & \multicolumn{3}{|c|}{ Setor Automobilístico } & \multicolumn{3}{|c|}{ Setor de Linha Branca } \\
\hline & \multicolumn{3}{|c|}{ Montadoras de Motores } & \multicolumn{3}{|c|}{ Montadoras de Linha Branca } \\
\hline & MM & MM & MM & MLB & MLB & MLB \\
\hline & 1 & 2 & 3 & 4 & 5 & 6 \\
\hline Clientes & $\begin{array}{l}\text { Montadora de } \\
\text { Veículos }\end{array}$ & $\begin{array}{l}\text { Montadora de Veículos } \\
\text { e montadora de outra } \\
\text { marca, para a qual } \\
\text { fornece motores } 1.8\end{array}$ & $\begin{array}{l}\text { As montadoras } \\
\text { de veículos de } \\
\text { ambos os lados } \\
\text { da joint venture }\end{array}$ & $\begin{array}{l}\text { Grandes lojas de } \\
\text { departamentos e } \\
\text { hipermercados }\end{array}$ & $\begin{array}{l}\text { Idem } \\
\text { MLB4 }\end{array}$ & $\begin{array}{l}\text { Idem } \\
\text { MLB4 }\end{array}$ \\
\hline Fornecedores & 150 & 100 & 92 & 346 & 225 & 115 \\
\hline
\end{tabular}


No que diz respeito ao setor de linha branca, cabe mencionar que a comparação entre cadeias será focada principalmente nas montadoras 4 e 5 , pois apresentam portes maiores em relação à 6 (nacional).

$\mathrm{O}$ aspecto que merece destaque é o fato de as cadeias deste setor serem ainda mais curtas do que as automotivas. Na maior parte dos casos, as cadeias iniciam-se a montante em grandes empresas siderúrgicas, metalúrgicas e petroquímicas, que fornecem materiais diretamente às montadoras (atuando, desse modo, no primeiro nível de suprimentos) e também aos fornecedores de primeiro nível delas (segundo nível de suprimentos).

Em menor proporção, algumas empresas (fornecedoras diretas) adquirem de fornecedores (os de segundo nível das montadoras) algumas peças e componentes, geralmente considerados simples do ponto de vista tecnológico. Desse modo, são mais raros os casos em que os fornecedores de primeiro nível adquirem (no segundo nível de suprimentos das montadoras) componentes mais complexos.

Apresentando diferentes políticas de suprimentos, a diversidade de modelos de produtos das montadoras MLB4 e MLB5 tem aumentado, o que tem feito o número de fornecedores de componentes também crescer.

Assim, enquanto as Montadoras 4 e 6 adotam a estratégia de possuir um fornecedor por item terceirizado e têm alguns fornecedores exclusivos, a Montadora 5 possui dois fornecedores por item e um conjunto maior de fornecedores no exterior.

Embora a Montadora 4 adquira em sua cadeia de suprimentos um conjunto maior de peças de maior valor agregado (módulos/sistemas) do que a Montadora 5, seus fornecedores são em geral de menor porte, quando comparados aos fornecedores da Montadora 5. Cabe lembrar que os fornecedores da Montadora 6 também são, em sua maioria, empresas de pequeno porte, geralmente nacionais.

As Montadoras 5 e 6 mantêm seus fornecedores localizados próximos às suas plantas, o que não ocorre com a Montadora 4. Esta última possui um conjunto de fornecedores mais distantes, localizados próximos a outra planta do grupo e que atendem a ambas as plantas.

Nas cadeias dos dois setores, as empresas constituíram redes de fornecedores com características gerais distintas - embora também com similaridades e com fornecedores comuns, que fazem parte de mais do que uma rede - e, em função dessas características, devem administrar o processo de cooperação tecnológica. Nessas redes, há fornecedores que detêm as tecnologias sobre componentes e há fornecedores - em geral os de menor porte e de capital nacional - que dependem de tecnologia oriunda das montadoras para desenvolverem e produzirem componentes.

\subsection{Relações entre empresas nas cadeias de suprimentos}

No setor automotivo, em geral, os critérios utilizados utilizados pelas montadoras para selecionar fornecedores são preço, qualidade e capacidade tecnológica. Enquanto a Montadora 1 prioriza o preço, e por conseguinte coloca qualidade e capacidade tecnológica em segundo plano, a Montadora 1 estabelece que o preço, a qualidade, a capacidade tecnológica e os serviços oferecidos têm a mesma importância. Para a Montadora 3, preço e qualidade são critérios com alto valor para a empresa.

Quanto aos fornecedores ativos, as três montadoras os avaliam por meio de auditorias de produtos e de processos, com base em normas de qualidade, e os classificam de acordo com o desempenho de cada um deles frente ao cumprimento dos itens exigidos. Os fornecedores que apresentam problemas recorrentes em seus produtos e/ou processos de produção recebem das montadoras prazos para corrigi-los, e no decorrer de tais prazos auditorias são feitas pelas montadoras.

Em geral, as montadoras de motores não possuem contato direto com outros níveis da cadeia, que não sejam os clientes e os fornecedores imediatos, embora possam ocorrer casos em que montadoras atuem diretamente em seus fornecedores não imediatos para obter ganhos em prazos de entrega, preços ou mesmo melhorias da qualidade dos produtos.

Enquanto as Montadoras 2 e 3 concentram suas bases de suprimentos em fornecedores de maior porte e capacidade tecnológica, preferencialmente empresas multinacionais e certificadas em normas de qualidade, a Montadora 1, embora também possua esse tipo de fornecedores, procura desenvolver um número significativo de empresas pequenas, ou seja, estabelecer programas de desenvolvimento para alguns de seus fornecedores para auxiliá-los a alcançar metas de desempenho superiores.

As Montadoras 2 e 3, principalmente a 3, procuram estabelecer relações de longo prazo com um número menor de fornecedores criteriosamente selecionados. Os fornecedores assumem responsabilidades quanto à tecnologia (na grande maioria dos casos), qualidade, entrega e embalagem dos componentes fornecidos, além dos estoques. Nestes casos, as montadoras teriam certa dificuldade para substituir fornecedores, se necessário.

Já a Montadora 1 combina relacionamentos similares aos observados entre as Montadoras 2 e 3 e seus fornecedores com relacionamentos com empresas pequenas, dependentes da montadora e desenvolvidos por ela em algum momento. E ainda, ao adotar como política de suprimentos a prática de possuir dois fornecedores por componente comprado, procura ampliar seu poder de barganha com os 
fornecedores, incentivando certa concorrência entre eles e mantendo menor dependência.

Merecem destaque as relações entre as montadoras e os fornecedores de componentes eletrônicos - trata-se de produtos mais complexos do ponto de vista tecnológico em que o conhecimento envolvido é de domínio de fornecedores multinacionais de maior porte. Estes componentes são desenvolvidos e fabricados exclusivamente para cada montadora (exclusividade por item) e as relações são muito próximas. Embora esse relacionamento seja tratado como "parceria" pelas montadoras, as negociações podem envolver conflitos.

Em geral as montadoras impõem fortes pressões (impondo melhorias em custos, qualidade, tecnologia, entregas, flexibilidades, etc.) às cadeias de suprimentos como um todo, mas os fornecedores que foram por elas desenvolvidos e/ou que mantêm uma montadora como principal cliente tendem a ser os mais atingidos.

A montadora 1 opera com milk run com alguns de seus fornecedores, o que permite tanto aumento na confiabilidade de entrega quanto reduções de custo por meio de consolidação dos fretes. A montadora 2 possui fornecedores instalados dentro de sua própria planta, o que promove a obtenção de níveis adequados de confiabilidade de entrega e de redução dos custos com estoques, praticamente os mesmos objetivos alcançados com o milk run adotado pela montadora 1.

Já no setor de linha branca, em geral, as montadoras 4 e 5 selecionam e avaliam os fornecedores de modo semelhante, considerando além de custos, a qualidade e outros aspectos (prazos de entrega, no caso da Montadora 4 e relações comerciais, no caso da Montadora 5). A partir dessa análise, as montadoras classificam seus fornecedores ativos de acordo com o desempenho apresentado e direcionam esforços aos mais críticos; aqueles que necessitam de auxílio para entregar peças obedecendo aos critérios estabelecidos. No caso da Montadora 6, a redução de custos recebe ainda maior ênfase, principalmente quando se trata de componentes de produtos mais populares.

Deve-se considerar, no entanto, que o fato das cadeias 4 e 5 serem constituídas por fornecedores de diferentes portes faz com que sejam distintos os poderes de negociação das montadoras: a montadora 4 , com fornecedores exclusivos e um número maior de empresas de pequeno porte, deve possuir maior poder de negociação, mas, por outro lado, deve prestar aos fornecedores auxílio constantemente. $\mathrm{O}$ desenvolvimento de fornecedores por parte dessas montadoras, no entanto, foi mais intenso no passado, e, atualmente, as empresas estão mais preparadas para fornecer os componentes dentro das especificações exigidas. No caso da Montadora 6, fornecedores são mais facilmente substituídos, já que a empresa está sempre buscando custos mais baixos.
Similar ao que ocorre com as montadoras de motores, as montadoras da linha branca apresentam maior dependência dos fornecedores de componentes eletrônicos. No entanto, os produtos da linha branca são relativamente menos complexos, e as pressões exercidas pelas montadoras nas cadeias como um todo parecem ser mais amenas.

Especificamente, no caso da produção de geladeiras, situação de dependência similar pode ser verificada no fornecimento dos compressores. Embora em um passado remoto algumas das montadoras de linha branca pudessem deter a tecnologia deste produto, hoje existem fornecedores especializados que são responsáveis pela produção e desenvolvimento de tais subsistemas.

As montadoras MLB 5 e MLB 6 não possuem relações com outros níveis da cadeia, a não ser com os fornecedores diretos. O contato com os outros níveis pode ocorrer apenas em casos de negociações mal resolvidas e em que a interferência da montadora pode auxiliar. Por sua vez, a MLB4 já teve casos de desenvolvimento de fornecedores pertencentes ao terceiro elo a montante de sua cadeia e participa de alguns dos processos de seleção de fornecedores nesse elo.

Semelhante ao que realiza a montadora de motores 1, a montadora 4 utiliza um sistema de milk run com seus fornecedores, dado que a maioria está localizada a uma distância máxima de $150 \mathrm{Km}$ da fábrica.

\section{Considerações finais}

Retomando as questões de pesquisa colocadas na introdução deste artigo, tem-se: Quais são as semelhanças e diferenças entre as cadeias de suprimentos nestes dois setores? Quais são os principais aspectos que influenciam e diferenciam as cadeias de suprimentos das montadoras de motores e da linha branca?

Quanto à primeira questão de pesquisa, abordam-se as semelhanças e diferenças encontradas ao se comparar as GCS estudadas nos dois setores. Das análises realizadas ao longo do artigo, pode-se mencionar como semelhanças:

- Ambos os setores passaram por um processo de reestruturação produtiva a partir dos anos 1990. No setor automotivo, ocorreu um forte processo de reestruturação com instalação de novas empresas, alteração de práticas gerenciais e fortes mudanças em produtos. No setor de linha branca, empresas nacionais foram adquiridas por grandes corporações estrangeiras, o que trouxe impactos na forma de gestão e nos próprios produtos;

- Em ambos os setores estudados, a participação de subsidiárias em projetos de desenvolvimento de 
produtos não é homogênea. Há, nos dois setores, montadoras que evoluíram de realizadoras de tropicalização para sedes de projetos, aumentando sua autonomia no desenvolvimento de produtos e processos;

- São raros os casos de fornecedores exclusivos (encontrados pontualmente nas cadeias de suprimentos de MM3 e MLB1), sendo bastante comum que fornecedores atendam simultaneamente a diversas montadoras em ambos os setores;

- Avaliação periódica de fornecedores e rankings de desempenho são práticas seguidas por quase todas as empresas da amostra;

- Em ambos os setores há tendência ao aumento do número de fornecedores no primeiro nível de fornecimento e isto está relacionado à ampliação do portfólio de produtos. Se tivessem sido mantidas as linhas de produtos, as práticas de CGS teriam provocado a redução dos números de fornecedores das montadoras;

- Há semelhanças entre políticas e práticas adotadas por montadoras do setor automobilístico e do setor de linha branca. As Montadoras 1 (de motores) e 4 (de linha branca), por exemplo, com conjuntos maiores (relativamente às concorrentes) de fornecedores de menor porte e de capacidade tecnológica limitada, devem despender esforço maior para desenvolvê-los e para garantir desempenho adequado.

Da mesma forma, pode-se também enumerar algumas diferenças entre as GCS identificadas nos casos estudados:

- As montadoras do setor automobilístico competem na fabricação dos mesmos produtos (motores) e, principalmente no caso das estabelecidas, nos mesmos segmentos de mercado. Já, no setor de linha branca, as montadoras fabricam diferentes tipos de produtos e podem se dedicar a distintos segmentos de mercado para um mesmo produto;

- A preocupação com custos ainda é muito importante na agenda gerencial da linha branca, ao passo que, no setor automotivo, tendo sido fortemente enfatizado no passado, pode ter se tornado um critério qualificador para a competição;

- No caso do setor de linha branca, pode-se identificar a presença de montadora (de pequeno porte, relativamente) de capital $100 \%$ nacional. No setor automotivo isto não ocorre;
- Embora as cadeias do segmento de motores sejam consideradas curtas, pois a maior parte de seus componentes é metálica (e a cadeia praticamente se inicia no segundo nível), as cadeias do setor de linha branca são, em geral, ainda mais curtas, pois há siderúrgicas, metalúrgicas e petroquímicas no primeiro e segundo níveis de suprimentos, nos quais as cadeias praticamente se iniciam;

- As montadoras do setor automobilístico tendem a ser mais exigentes em suas cadeias de suprimentos. Fornecedores que atendem a ambos os setores acabam gerando melhorias nos produtos da linha branca devido à implementação de programas e técnicas exigidos pelas montadoras automobilísticas;

No setor de linha branca, há maior proximidade entre a montadora e os fornecedores de segundo nível, como no caso da MBL4, que apresenta desenvolvimento de subfornecedores, e das MLB5 e 6, que realizam negociações comerciais diretamente com fornecedores de segundo nível.

Desta forma, do ponto de vista da Gestão da Cadeia de Suprimentos, pode-se afirmar que há semelhanças importantes entre as cadeias de suprimentos estudadas. Cabe recuperar que as cadeias estudadas pertencem a setores com características gerais semelhantes: oligopólios industriais, fabricantes de bens de consumo duráveis, dominados por grandes empresas transnacionais. As experiências recentes (mesmo que distintas) de reestruturação de seus setores, ausência de fornecedores exclusivos e ampliação da base de fornecimento são exemplos de similaridades. Contudo, diferenças puderam ser encontradas no que tange à sazonalidade de demanda, ao comprimento (quantidade de elos) das cadeias, às relações com fornecedores de primeiro nível e interação com fornecedores de segundo nível. Além disso, algumas questões variaram dentro dos próprios setores, como o grau de terceirização das empresas.

Quanto à questão do equilíbrio (ou desequilíbrio) de poder de negociação nas cadeias de suprimentos, dois exemplos são dignos de registro aqui: o caso do segmento de eletrônicos no setor automotivo e o de compressores no setor de linha branca (geladeiras). De forma similar, em algum momento do passado, as montadoras detiveram o conhecimento acerca da tecnologia destes componentes, mas com a terceirização criaram-se fornecedores especializados e que assumiram a responsabilidade pelo desenvolvimento tecnológico destes componentes.

$\mathrm{O}$ aumento do poder de barganha dos fornecedores não implicou, entretanto, possíveis ameaças às montadoras já que ao longo do tempo, em muitos casos, foram se desenvolvendo relações de parceria e de longo prazo. 
No tocante à segunda questão de pesquisa, cerne das análises realizadas ao longo da seção anterior, observa-se que as três cadeias de suprimentos estudadas no setor automobilístico, assim como as três cadeias de suprimentos do setor de linha branca, apresentam diferenças estruturais importantes, que fazem com que as relações entre empresas, no interior de cada uma delas, sejam também distintas. Entre outros aspectos, as montadoras apresentaram diferentes níveis de terceirização de componentes, diferentes localizações de suas plantas em relação aos fornecedores e números de fornecedores e política de suprimentos também diferenciados.

Pode ser verificado que essas empresas apresentam conjunto de critérios semelhantes em processos de seleção e avaliação de fornecedores, mas a ordem de importância dos critérios em cada conjunto é diferente.

Assim, em cada setor, embora as prioridades competitivas das montadoras sejam semelhantes, as decisões e práticas relacionadas à gestão da cadeia de suprimentos são distintas. Pode-se então conjeturar que, mesmo possuindo objetivos estratégicos similares em alguma medida, as empresas adotam práticas e configurações de GCS diferentes, e os objetivos priorizados são alcançados por vias distintas.

Destaca-se, finalmente, que não se tem como objetivo deste trabalho a obtenção de resultados generalizáveis, mas apenas a reunião de evidências que fomentem a discussão e a evolução da literatura sobre o tema.

Novas pesquisas devem ser realizadas no sentido de comparar cadeias de suprimentos de outros setores, de forma a prosseguir com a proposta de trabalho aqui apresentada, ou mesmo investigar novas cadeias nos dois setores aqui tratados. Além disso, pesquisas que contemplem, nas cadeias de suprimentos, os diversos elos a montante e a jusante de empresas montadoras são também necessárias.

\section{Agradecimentos}

À FAPESP - Fundação de Amparo à Pesquisa do Estado de São Paulo.

\section{Referências}

ALVAREZ, R. R. O setor automotivo no Rio de Janeiro: Uma analise na inserção dos fabricantes locais de autopeças na cadeia automotiva. 2004. 932 f. Tese (Doutorado em Ciências em Engenharia de Produção)Universidade Federal do Rio de Janeiro, Rio de Janeiro, 2004.

ALVES FILHO, A. G. et al. Pressupostos do gerenciamento da cadeia de suprimentos: evidências de estudos sobre a indústria automobilística. Gestão \& Produção, v. 11, n. 3, p. 275-288, 2004. http://dx.doi.org/10.1590/ S0104-530X2004000300003

ASSUMPÇÃO, M. R. P. Reflexão para gestão tecnológica em cadeias de suprimentos. Gestão \& Produção, v. 10 , n. 3, p. 345-362, 2003. http://dx.doi.org/10.1590/ S0104-530X2003000300009

BANDEIRA, R. A. M.; MELLO, L. C. B. B.; MAÇADA, A. C. G. Relacionamento interorganizacional na cadeia de suprimentos: um estudo de caso na indústria da construção civil. Produção, v. 19, n. 2, p. 376-387, 2009. http://dx.doi.org/10.1590/S0103-65132009000200012

BURGESS, K.; SINGH, P. J.; KOROGLU, R. Supply chain management: a structured literature review and implications for future research. International Journal of Operations \& Production Management, v. 26, n. 7, p. 703-729, 2006. http://dx.doi. org/10.1108/01443570610672202

CERRA, A. L.; MAIA, J.; ALVES FILHO, A. G. Aspectos estratégicos, estruturais e relacionais de três cadeias de suprimentos automotivas. Gestão \& Produção, v. 14, n. 2, p. 253-265, 2007. http://dx.doi.org/10.1590/ S0104-530X2007000200005

CERRA, A. L. et al. Estratégias de operações e tecnológicas de empresas do setor de linha branca. In: ENCONTRO NACIONAL DE ENGENHARIA DE PRODUÇÃO, 28., 2008, Rio de Janeiro. Anais...

CHENG, H.; CHEN, C.; MAO, C. The evolutionary process and collaboration in supply chains. Industrial Management \& Data Systems, v. 110, n. 3-4, p. 453-474, 2010.

CHOPRA, S.; MEINDL, P. Gerenciamento da cadeia de suprimentos: estratégia, planejamento e operação. São Paulo: Prentice Hall, 2003.

CHRISTOPHER, M. Logistics and supply chain management. London: Pitman Publishing, 1992.

COSTA, J. C.; MAÇADA, A. C. G. Gestão da informação interorganizacional na cadeia de suprimentos. Revista de Administração de Empresas, v. 8, n. 2, Art. 10, 2009.

CUNHA, A. M. As novas cores da linha branca: os efeitos da desnacionalização da indústria brasileira de eletrodomésticos nos anos 1990. 2003. Tese (Doutorado em Ciências Econômicas)-Instituto de Economia, Universidade Estadual de Campinas, Campinas, 2003.

ELLRAM, L.; BILLINGTON, C. Purchasing leverage considerations in the outsourcing decision. European Journal of Purchasing \& Supply Management, v. 7, n. 1, p. 15-27, 2001. http://dx.doi.org/10.1016/ S0969-7012(00)00004-6

GARVIN, D. A. Manufacturing strategy planning. California Management Review, v. 35, n. 4, p. 85-106, 1993. http://dx.doi.org/10.2307/41166756

HANDFIELD, R. B.; KRAUSE, D. R.; SCANNELL, T. V. Avoid the pitfalls in supplier development. Sloan Management Review, v. 41, n. 2, p. 37-49, 2000.

HILSDORF, W. C.; ROTONDARO, R. G.; PIRES, S. R. I. Integração de processos na cadeia de suprimentos e desempenho do serviço ao cliente: um estudo na indústria calçadista de Franca. Gestão \& Produção, v. 16, n. 2, p. 232-244, 2009. http://dx.doi.org/10.1590/ S0104-530X2009000200007

LAMBERT, D. M.; EMMELHAINZ, M. A.; GARDNER, J. T. Developing and implementing Supply Chain Partnerships. The International Journal of Logistics Management, v. 9, n. 2, p. 1-17, 1996. http://dx.doi. org/10.1108/09574099810805807 
LAMBERT, D. M.; COOPER, M. C.; PAGH, J. D. Supply chain management: implementation issues and research opportunities. The International Journal of Logistics Management, v. 9, n. 2, p. 1-18, 1998. http://dx.doi. org/10.1108/09574099810805807

LAMMING, R. Beyond partnership: strategies for innovation and lean supply. London: Prentice-Hall, 1993. 294 p. (The Manufacturing Practioner Series).

LUMMUS, R. R.; VOKURKA, R. J. Defining supply chain management: a historical perspective and practical guidelines. Industrial Management \& Data Systems, v. 99, n. 1, p. 11-17, 1999. http://dx.doi. org/10.1108/02635579910243851

MAIA, J. L. Alinhamento entre a estratégia de operações e a gestão estratégica da logística: estudos de caso no setor automotivo brasileiro. 2006. 230 f. Dissertação (Mestrado em Engenharia de Produção- Universidade Federal de São Carlos, São Carlos, 2006.

MARTINS, M. F Análise da função suprimentos nas empresas de manufatura: o caso das empresas da indústria de linha branca. 1999. 196 f. Tese (Doutorado em Engenharia Mecânica)-Escola de Engenharia de São Carlos, Universidade de São Paulo, São Carlos, 1999.

MENTZER, J. T. et al. Defining supply chain management. Journal of Business Logistics, v. 22, n. 2, p. 1-25, 2001. http://dx.doi.org/10.1002/j.2158-1592.2001.tb00001.x

MIRANDA, J. L. Procedimento para análise da viabilidade da utilização de operadores logísticos na cadeia de suprimentos. 2002. $171 \mathrm{f}$. Tese (Doutorado em Engenharia Mecânica)-Escola de Engenharia de São Carlos, Universidade de São Paulo, São Carlos, 2002.

NEUMANN, C. S. R.; RIBEIRO, J. L. D. Desenvolvimento de fornecedores: um estudo de caso utilizando a troca-rápida de ferramentas. Revista Produção, v. 14, n. 1, p. 44-51, 2004. http://dx.doi.org/10.1590/ S0103-65132004000100005

OLIVEIRA, J. B.; LEITE, M. S. A. Modelo analítico de suporte à configuração e integração da cadeia de suprimentos. Gestão \& Produção, v. 17, n. 3, p. 447-463, 2010. http://dx.doi.org/10.1590/ S0104-530X2010000300002

PADOVANI, C. B. O papel a governança na cadeia de suprimento automotiva - fornecedores de primeiro e segundo nível. In: SIMPÓSIO DE ADMINISTRAÇÃO DA PRODUÇÃO, LOGÍSTICA E OPERAÇÕES INTERNACIONAIS, 10., 2007, São Paulo. Anais... São Paulo: EAESP-FGV, 2007.

PARK, J. et al. An integrative framework for supplier relationship management. Industrial Management \& Data Systems, v. 110, n. 3-4, p. 495-515, 2010. http:// dx.doi.org/10.1108/02635571011038990
PIRES, S. R. I. Gestão da Cadeia de Suprimentos (Supply Chain Management): conceitos, estratégias e casos. São Paulo: Atlas, 2004. 310 p.

PIRES, S. R. I.; SACOMANO NETO, M. Características estruturais, relacionais e gerenciais na cadeia de suprimentos de um condomínio industrial na indústria automobilística. Produção, v. 20, n. 2, p. 172-185, 2010. http://dx.doi.org/10.1590/S0103-65132010005000032

ROTTA, I. S. Mini-fábrica: Uma nova proposta de arranjo produtivo e organizacional híbrido em uma empresa do setor eletroeletrônico. 2004. 268 f. Tese (Doutorado em Engenharia de Produção)-Departamento de Engenharia de Produção, Universidade Federal de São Carlos, São Carlos, 2004.

SANTOS, A. C.; FORCELLINI, F. A. Avaliação do envolvimento dos fornecedores no processo de desenvolvimento de produtos (PDP) a partir de um modelo de referência para a indústria de alimentos. In: CONGRESSO BRASILEIRO DE GESTÃO DE DESENVOLVIMENTO DE PRODUTOS, 5., 2005, Curitiba. Anais...

SANTOS, C. B.; KATO, H. T.; FREGA, J. R. Orientação da Gestão da Cadeia e desempenho do fornecedor na Indústria Automobilística Nacional. In: SIMPÓSIO DE ADMINISTRAÇÃO DA PRODUÇÃO, LOGÍSTICA E OPERAÇÕES INTERNACIONAIS, 9., 2006, São Paulo. Anais... São Paulo: FGV-EAESP, 2006.

TAN, K. C. Supply Chain Management: practices, concerns, and performance issues. The Journal of Supply Chain Management, v. 38, n. 4, p. 42-53, 2002. http://dx.doi. org/10.1111/j.1745-493X.2002.tb00119.x

TEIXEIRA, R.; LACERDA, D. P. Gestão da Cadeia de Suprimentos: análise dos artigos publicados em alguns periódicos acadêmicos entre os anos de 2004 e 2006. Gestão \& Produção, v. 17, n. 1, p. 207-227, 2010. http://dx.doi.org/10.1590/S0104-530X2010000100016

TRATT, S. R. B.; MORAES, M. C. B.; ALPERSTEDT, G. D. A terceirização de atividades-fim em uma siderúrgica: ameaça ou oportunidade? In: SIMPÓSIO DE ADMINISTRAÇÃO DA PRODUÇÃO, LOGÍSTICA E OPERAÇÕES INTERNACIONAIS, 9., 2006, São Paulo. Anais... São Paulo: FGV-EAESP, 2006.

WONG, C. et al. Towards a theory of supply chain alignment enablers: a systematic literature review. Supply Chain Management: An International Journal, v. 17, n. 4, p. 419-421, 2011. http://dx.doi. org/10.1108/13598541211246567

YIN, R. Estudo de caso: planejamento e métodos. Tradução Daniel Grassi. 3. ed. Porto Alegre: Bookman, 2005. 